\title{
PERBEDAAN ASUPAN ENERGI, AKTIVITAS FISIK, DAN STATUS GIZI ANTARA ANAK USIA 4-5 TAHUN DI TAMAN KANAK-KANAK DAERAH URBAN DAN SUBURBAN
}

\author{
Usydatul Falasifah, Etika Ratna Noer*) \\ Program Studi Ilmu Gizi Fakultas Kedokteran Universitas Diponegoro \\ J1.Dr.Sutomo No.18, Semarang, Telp (024) 8453708, Email : gizifk@ undip.ac.id
}

\begin{abstract}
Background : Health problems that often encountered among 4-5 years old children were caused by nutritional factors. Energy intake and physical activity were factors that could affect nutritional status. The differences in residential areas could lead to differences in nutritional status at children 4-5 years old. The purpose of this study was to determine each difference in energy intake, physical activity, and nutritional status among 4-5 years old children in kindergarten urban and suburban.

Methods : The design of this study was cross sectional design. The study subjects consist of 34 children in urban areas and 34 children in suburban areas selected by purposive sampling. The data examined including energy intake derived from food recall form, physical activity obtained from the recall form of physical activity, and nutritional status measured by the value of the Z - scores based on the BMI/A. Data were analyzed using the Mann - Whitney test.

Results : There was no difference of mean energy intake and physical activity between two groups, whereas there was a difference of mean nutritional status between two groups. There was no differences in energy intake $(p=0.080)$ and physical activity $(p=0.272)$ between the two groups. There was a difference of nutritional status between the two groups $(p=0.050)$.

Conclusions : There was no difference in energy intake and physical activity among 4-5 years old children in kindergarten urban and suburban. There was a difference between the nutritional status of 4-5 years old children in kindergarten urban and suburban.
\end{abstract}

Keywords : energy intake; physical activity; nutritional status; 4-5 years old children; kindergarten; urban; suburban

\begin{abstract}
ABSTRAK
Latar belakang : Masalah kesehatan yang sering dijumpai dikalangan anak usia 4-5 tahun disebabkan oleh faktor gizi. Asupan energi dan aktivitas fisik merupakan faktor yang dapat mempengaruhi status gizi. Adanya perbedaan wilayah tempat tinggal dapat menyebabkan adanya perbedaan status gizi pada anak usia 4-5 tahun. Tujuan penelitian ini adalah mengetahui perbadaan asupan energi, aktivitas fisik, dan status gizi antara anak usia 4-5 tahun di taman kanak-kanak daerah urban dan suburban.

Metode : Subyek penelitian dengan desain cross-sectional ini terdiri dari 34 anak berada di daerah urban dan 34 anak berada di daerah suburban yang dipilih secara purposive sampling. Data yang diteliti meliputi asupan energi yang diperoleh dari formulir food recall, aktivitas fisik diperoleh dari formulir recall aktivitas fisik, dan status gizi diukur dengan nilai Z-skor berdasarkan IMT/U. Analisis data menggunakan uji Mann-Whitney.

Hasil : Rerata asupan energi dan aktivitas fisik antara kedua kelompok tidak ada beda, sedangkaan rerata status gizi antara kedua kelompok terdapaat beda. Tidak terdapat perbedaan asupan energi $(p=0,080)$ dan aktivitas fisik $(p=0.272)$ antara kedua kelompok. Terdapat perbadaan status gizi antara kedua kelompok $(p=0,050)$.

Simpulan : Tidak terdapat perbedaan asupan energi dan aktivitas fisik antara anak usia 4-5 tahun di taman kanakkanak daerah urban dan suburban. Terdapat perbedaan status gizi antara anak usia 4-5 tahun di taman kanak-kanak daerah urban dan suburban.
\end{abstract}

Kata kunci : asupan energi; aktivitas fisik; status gizi; anak usia 4-5 tahun; urban; suburban

\section{PENDAHULUAN}

Masalah kesehatan yang sering dijumpai dikalangan anak usia 4-5 tahun salah satunya disebabkan oleh faktor gizi. ${ }^{1}$ Anak usia 4-5 tahun merupakan masa saat anak menjadi konsumen aktif dalam memilih makanan sehingga anak sudah dapat memilih sendiri makanan yang diinginkan. ${ }^{2}$ Gizi kurang pada masa ini akan mengakibatkan gangguan pertumbuhan fisik dan perkembangan mental. ${ }^{1}$ Selain gizi kurang, ditemukan juga masalah kesehatan pada anak yang disebabkan gizi lebih. Jika gizi lebih terus berlanjut sampai dewasa, anak akan berisiko menderita penyakit degeneratif seperti diabetes, tekanan darah tinggi, penyakit jantung, stroke, gout. ${ }^{3}$ Prevalensi anak gizi kurang menurut Riset Kesehatan Dasar tahun 2010 lebih banyak terjadi di daerah perdesaan (14\%) daripada di daerah urban $(12,5 \%)$. Sedangkan prevalensi anak gizi lebih, banyak terjadi di daerah urban $(14,6 \%)$ daripada di daerah perdesaan $(13,4 \%){ }^{4}$ Perbedaan masalah status gizi tersebut antara lain disebabkan oleh perbedaan asupan energi dan aktivitas fisik di kedua wilayah tersebut.

\footnotetext{
${ }^{*}$ Penulis Penanggungjawab
} 
Asupan energi yang rendah pada masyarakat suburban umumnya disebabkan kemiskinan, kurangnya persediaan pangan dan kurangnya pengetahuan masyarakat tentang gizi. ${ }^{5}$ Penelitian di Pakistan menunjukkan bahwa masyarakat ekonomi menengah kebawah memiliki risiko kekurangan gizi akibat kurangnya asupan. ${ }^{6}$ Penelitian di Pati juga menunjukan bahwa semakin kecil pendapatan keluarga, maka semakin besar persentase anak yang kekurangan gizi. ${ }^{5}$ Masyarakat di daerah urban lebih menyukai makanan cepat saji dengan kandungan energi tinggi karena disibukkan dengan pekerjaan dan dipengaruhi oleh perkembangan zaman. Hal itu menyebabkan tingginya prevalensi gizi lebih di daerah urban.

Asupan energi yang diasup oleh anak tidak lepas dari perilaku praktik pemberian makan yang dilakukan oleh orang tua. Penelitian yang dilakukan oleh Ritayani menunjukkan bahwa praktik pemberian makan yang baik sangat mendukung tercapainya status gizi anak yang baik. ${ }^{7}$ Beberapa penelitian menunjukkan bahwa praktik pemberian makan yang salah dapat mengakibatkan anak sulit makan. ${ }^{8,9}$ Penelitian Yulia juga menunjukkan bahwa semakin baik pola asuh maka semakin baik pula status gizi anak. ${ }^{10}$

Perbedaan status gizi anak di kedua wilayah tersebut juga disebabkan oleh tingkat aktivitas fisik. Anak di daerah urban dengan ekonomi menengah keatas sudah terbiasa dengan kemajuan teknologi dan tersedianya fasilitas modern serta sempitnya lahan bermain. ${ }^{2,12} \mathrm{Hal}$ tersebut menyebabkan anak cenderung pasif dan memiliki gaya hidup santai sehingga aktivitas mereka kurang. ${ }^{11}$ Sedangkan anak di daerah suburban yang belum begitu terpengaruh dengan kemajuan teknologi dan masih tersedia lahan untuk bermain, sehingga aktivitas fisik mereka lebih banyak dibandingkan anak di daerah urban. ${ }^{13}$

Berdasarkan paparan di atas, peneliti tertarik untuk mengetahui apakah ada perbedaan asupan energi, aktivitas fisik, dan status gizi antara anak usia 4-5 tahun pada TK di daerah urban dan suburban. Penelitian ini diharapkan dapat memberikan informasi pada masyarakat tentang pentingnya mengatur asupan energi dan aktifitas fisik untuk mengontrol berat badan anak agar mencapai status gizi normal dan dapat dijadikan sumber acuan yang dapat digunakan untuk penelitian selanjutnya dalam mengembangkan ilmu pengetahuan.

\section{METODE PENELITIAN}

Penelitian ini termasuk dalam lingkup gizi masyarakat dengan desain cross-sectional.
Pelaksanaan penelitian dilakukan pada bulan April - Mei 2014. Pengambilan subjek penelitian dengan metode purposive sampling. Subjek dalam penelitian ini adalah anak TK usia 4-5 tahun. Penelitian dilakukan di daerah urban dan suburban di Kabupaten Banyumas. Daerah urban merupakan suatu daerah yang memiliki suasana kehidupan dan penghidupan modern. ${ }^{14}$ Dalam penelitian ini dipilih 2 kecamatan yang terletak di daerah urban, yaitu Kecamatan Purwokerto Utara dan Kecamatan Purwokerto Timur. Sedangkan daerah suburban merupakan suatu area yang lokasinya dekat dengan pusat kota dengan luas mencakup daerah penglaju. ${ }^{14}$ Dalam penelitian ini dipilih 2 kecamatan yang terletak di daerah suburban, yaitu Kecamatan Karanglewas dan Kecamatan Patikraja.

Kriteria inklusi dalam penelitian ini yaitu usia 4-5 tahun dan tidak dalam keadaan sakit atau dalam perawatan dokter, untuk kelompok urban tercatat sebagai murid TK daerah urban, sedangkan untuk kelompok suburban tercatat sebagai murid TK daerah suburban. Kriteria eksklusi dalam penelitian ini adalah anak sakit, anak pindah sekolah, dan mengundurkan diri sebagai subjek penelitian saat penelitian masih berlangsung.

Skrining dilakukan pada seluruh murid pada 8 TK di 4 kecamatan yaitu TK Negeri Pembina 2 di Kecamatan Purwokerto Utara; TK Al-Irsyad, TK Aisiyah 1 Purwokerto, dan TK Sokanegara di Kecamatan Purwokerto Timur; TK Diponegoro 53 Pasir Kulon dan TK Aisiyah Karanglewas Kidul di Kecamatan Karanglewas; serta TK Pertiwi Pegalongan dan RA MNU Diponegoro 104 Kedungwringin di Kecamatan Patikraja. Jumlah subjek penelitian yang memenuhi kriteria inklusi dipilih sebanyak 64 anak yang terdiri dari masingmasing 32 anak untuk daerah urban dan daerah suburban. Orang tua anak yang telah memenuhi kriteria inklusi dimohon kesediaannya untuk menjadi responden penelitian dengan mengisi informed consent. Responden yang telah mengisi informed consent kemudian diambil data berupa data karakteristik anak, data asupan energi anak menggunakan formulir recall, dan data aktivitas fisik anak.

Data karakteristik yaitu meliputi identitas orang tua dan identitas subjek. Data identitas orang tua meliputi pekerjaan ibu dan pendapatan keluarga. Pekerjaan ibu digolongkan dalam 2 kategori yaitu bekerja apabila ibu bekerja dan tidak bekerja apabila ibu hanya sebagai ibu rumah tangga. Pendapatan keluarga diukur berdasarkan UMR Kabupaten Banyumas yang kemudian digolongkan menjadi 2 kategori yaitu 
tinggi apabila pendapatan keluarga $>\mathrm{Rp} 1.000 .000$ dan rendah apabila $<\mathrm{Rp} 1.000 .000$.

Data karakteristik anak meliputi usia dan jenis kelamin anak. Asupan energi diperoleh melalui wawancara menggunakan formulir food recall selama $3 \times 24$ jam tidak berturut-turut kemudian diolah dan dianalisa menggunakan software Nutrisurvey. Kategori asupan energi kurang jika $\leq 89 \%$, cukup jika $90-119 \%$, dan lebih jika $\geq 120 \%$ dari total kebutuhan. ${ }^{14}$ Data aktivitas fisik diperoleh dengan mencatat semua kegiatan yang dilakaukan sehari-hari menggunakan formulir recall aktivitas fisik selama $3 \times 24$ jam tidak berturutturut. Data aktivitas fisik dikelompokkan menurut Physical Activity Level (PAL) yang di dapatkan dari jumlah energi yang dikeluarkan (Physical Activity Ratio ( PAR) dari tiap kegiatan, dikalikan dengan alokasi waktu saat melakukan kegiatan dinyatakan dalam jam, kemudian dibagi 24 jam yang kemudian di rata - rata selama 3 hari. Aktivitas fisik dikatakan sangat ringan jika nilai $\mathrm{PAL}<1,45$, ringan jika nilai PAL 1,45-1,59, dan sedang jika nilai PAL $\geq 1,60 .{ }^{16}$ Data status gizi diperoleh dari hasil pengukuran antropomerti berat badan dan tinggi badan kemudian dihitung berdasarkan z-skor indeks IMT/U yang kemudian dikategorikan gemuk jika
$\mathrm{IMT} / \mathrm{U}>2,0 \mathrm{SD}$, normal jika IMT/U -2,0 - 2,0 SD, dan kurus jika IMT/U <-2,0 SD. ${ }^{17}$

Data yang dikumpulkan yaitu identitas subjek, IMT, data asupan energi, dan aktivitas fisik. Data yang telah diperoleh kemudian dianalisis menggunakan program SPSS v.20.00 dengan derajat kepercayaan $95 \%(\alpha=0,05)$. Analisa data untuk mengetahui perbedaan menggunakan uji Independent T-test untuk data berdistribusi normal dan untuk data berdistribusi tidak normal menggunakan uji Mann-Whitney.

\section{HASIL PENELITIAN \\ Karakteristik Subjek Penelitian}

Subjek penelitian berjumlah 64 anak yang terdiri dari 32 anak yang terdaftar menjadi murid TK di daerah urban dan 32 anak yang terdaftar menjadi murid TK di daerah suburban. Anak pada kelompok urban dan suburban sebagian besar berumur 5 tahun dan berjenis kelamin perempuan. Sebagian besar ibu pada kelompok urban bekerja, sedangkan sebagian besar pada kelompok suburban tidak bekerja. Keluarga pada kelompok urban berstatus ekonomi menengah keatas, sedangkan pada kelompok suburban sebagian besar berstatus ekonomi menengah kebawah. Karakteristik subjek penelitian dapat dilihat pada tabel 1 .

Tabel 1. karakteristik subjek penelitian

\begin{tabular}{lcccc}
\hline \multirow{2}{*}{ Variabel } & \multicolumn{2}{c}{ Urban } & \multicolumn{2}{c}{ Suburban } \\
\cline { 2 - 5 } & $\mathrm{N}$ & $\%$ & $\mathrm{n}$ & $\%$ \\
\hline Identitas Subjek & & & & \\
Umur & 12 & 37,5 & 4 & 12,5 \\
4 tahun & 20 & 62,5 & 28 & 87,5 \\
5 tahun & & & & \\
Jenis Kelamin & 15 & 46,9 & 14 & 43,8 \\
Laki - laki & 17 & 53,1 & 18 & 56,2 \\
Permpuan & & & & \\
\hline Identitas Orang Tua & & & & \\
Pekerjaan Ibu & 23 & 71,9 & 7 & 21,9 \\
Bekerja & 9 & 28,1 & 25 & 78,1 \\
Tidak Bekerja & & & & \\
Pendapatan Keluarga & 32 & 100 & 2 & 6,2 \\
$>$ Rp 1.000.000 & 0 & 0 & 30 & 93,8 \\
\hline Rp 1.000.000 & & & & \\
\hline
\end{tabular}

Perbedaan Asupan Energi, Aktivitas Fisik, dan Status Gizi pada Anak Usia 4-6 Tahun

Rerata asupan energi pada kelompok urban sebesar 1697,8 kkal/hari , sedangkan kelompok suburban 1610,5 kkal/hari. Aktivitas fisik yang dilakukan oleh kedua kelompok cenderung pasif dan tidak ada beda. Ini ditunjukkan dengan nilai rerata PAL sebesar 1,50 yang termasuk dalam kategori ringan. Status gizi berdasarkan IMT/U pada kelompok urban memiiki rerata 1,07 SD, hasil ini lebih besar jika dibandingkan dengan kelompok suburban yaitu 0,40 SD. Meskipun memiliki perbedaan rerata status gizi, namun rerata kedua 
kelompok masih termasuk dalam kategori status gizi normal.

Tabel 2. Asupan energi, aktivitas fisik, dan status gizi pada kelompok urban dan suburban

\begin{tabular}{|c|c|c|c|c|c|c|c|}
\hline & \multicolumn{3}{|c|}{ Urban } & \multicolumn{3}{|c|}{ Suburban } & \multirow{2}{*}{ p-value } \\
\hline & Min & Maks & 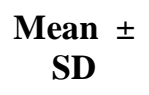 & Min & maks & $\begin{array}{l}\text { Mean } \pm \\
\text { SD }\end{array}$ & \\
\hline Asupan Energi (kkal) & 1237.4 & 2149 & $\begin{array}{c}1697.8 \pm \\
247.5\end{array}$ & 1327.5 & 2104.3 & $\begin{array}{c}1610.5 \pm \\
189.1\end{array}$ & 0.080 \\
\hline Tingkat aktivitas fisik & 1.35 & 1.64 & $\begin{array}{c}1.50 \pm \\
0.07\end{array}$ & 1.38 & 1.62 & $\begin{array}{c}1.50 \pm \\
0.06\end{array}$ & 0.272 \\
\hline Z-skor IMT/U (SD) & -2.03 & 3.56 & $\begin{array}{c}1.07 \pm \\
1.44\end{array}$ & -2.08 & 2.63 & $\begin{array}{c}0.40 \pm \\
1.36\end{array}$ & 0.050 \\
\hline
\end{tabular}

Berdasarkan uji normalitas data pada tabel 2, yaitu data asupan energi, aktivitas fisik dan data status gizi, ketiga data tersebut berdistribusi tidak normal, sehingga ketiga data tersebut dianalisis menggunakan uji Mann-Whitney. Berdasarkan hasil analisis menggunakan uji MannWhitney dapat disimpulkan bahwa tidak terdapat perbedaan asupan energi pada kedua kelompok $(\mathrm{p}=0,080)$. Tidak terdapat perbedaan aktivitas fisik pada kedua kelompok $(\mathrm{p}=0,272)$. Terdapat perbedaan status gizi pada kedua kelompok $(\mathrm{p}=0,050)$.

\section{PEMBAHASAN}

Perbedaan Asupan Energi pada Anak Usia Taman Kanak-Kanak di Daerah Urban dan Suburban

Asupan energi merupakan salah satu faktor yang dapat mempengaruhi status gizi anak. Asupan energi dalam penelitian ini didapatkan dari hasil food recall salama $3 \times 24$ jam tidak berturutturut. Rerata asupan energi pada kedua kelompok termasuk dalam kategori cukup yaitu 1698 kkal pada kelompok urban dan 1611 kkal pada kelompok suburban. Hasil dari penelitian ini menunjukkan bahwa tidak terdapat perbedaan asupan energi pada kedua kelompok $(\mathrm{p}=0,080)$. Tidak adanya perbedaan pada kedua kelompok dikarenakan pola makan dan jenis makanan yang dikonsumsi oleh kedua kelompok cenderung sama.

Hasil dari penelitian menunjukkan bahwa anak pada kedua kelompok sering diberikan makanan sesuai dengan yang anak inginkan tanpa memperhatikan jumlah dan jenis makanaan yang tepat untuk mereka. Hal tersebut dilakukan karena orang tua maupun pengasuh khawatir jika permintaan anak tidak dipenuhi maka anak tidak mau makan. Makanan yang sering dikonsumsi oleh kedua kelompok yaitu makanan tinggi energi seperti mie instant, roti, sosis, nugget, siomay, dan bakso. Sebagian besar anak pada kedua kelompok hampir tidak pernah mengkonsumsi sumber serat seperti buah dan sayur. Pola makan yang tidak seimbang ini dipengaruhi oleh sikap dan pemilihan makanan yang diberikan kepada anak kurang bervariasi. Anak pada kelompok urban sebagian besar diasuh oleh pengasuh karena orang tua mereka bekerja $(71,9 \%)$, sedangkan anak pada kelompok suburban sebagian besar diasuh oleh orang tua $(78,1 \%)$. Pengasuh pada kelompok urban dan orang tua pada kelompok suburban memiliki pengetahuan yang kurang terutama tentang gizi. Hal ini yang mempengaruhi anak pada kedua kelompok memiliki pola makan yang tidak seimbang.

Asupan makan yang tidak seimbang dapat menimbulkan masalah gizi. Kekurangan gizi pada anak dapat menyebabkan timbulnya berbagai penyakit dan infeksi. Namun, jika berlebih akan dapat menimbulkan obesitas. Pola asuh orang tua berpengaruh terhadap pola makan anak. Beberapa penelitian menunjukkan bahwa praktik pemberian makan yang salah dapat mengakibatkan anak sulit makan. ${ }^{8.9}$ Selain pola asuh, status ekonomi juga dapat mempengaruhi status gizi. Penelitian menunjukkan bahwa masyarakat ekonomi menengah kebawah memiliki risiko kekurangan gizi akibat kurangnya asupan makan. ${ }^{6}$

Perbedaan Aktivitas Fisik pada Anak Usia Taman Kanak-Kanak di Daerah Urban dan Suburban

Faktor lain yang berpengaruh terhadap status gizi adalah akivitas fisik. Besarnya aktivitas fisik dalam penelitian ini diperoleh dari formulir recall aktivitas fisik selama $3 \times 24$ jam tidak berturutturut. Kemudian dari hasil itu dihitung menggunakan rumus Physical Activity Level (PAL). Sebagian besar anak pada kedua kelompok (urban 56,3\%; suburban 81,3\%) mempunyai nilai PAL 
yang masuk dalam kategori ringan. Hasil dari penelitian ini menunjukkan tidak terdapat perbedaan aktivitas fisik pada kedua kelompok $(\mathrm{p}=0,272)$. Tidak adanya perbedaan nilai aktivitas fisik pada kedua kelompok dikarenakan anak pada kedua kelompok sama-sama memiliki gaya hidup yang cenderung pasif.

Anak pada kelompok urban lebih banyak menghabiskan waktu di rumah untuk menonton televisi, bermain gadget, dan bermain laptop. Adanya fasilitas yang disediakan oleh orang tua membuat anak semakin pasif dan kurang beraktivitas fisik. Hal ini dilakukan dengan alasan orang tua lebih leluasa untuk mengawasi anak dalam bermain. Kegiatan yang dilakukan di akhir pekan yaitu bersantai di rumah dan sesekali pergi ke pusat perbelanjaan. Anak pada kelompok suburban juga cenderung memiliki gaya hidup santai. Sebagian besar anak pada kelompok suburban menghabiskan waktu bermain di luar rumah. Meskipun aktivitas mereka dilakukan di luar rumah, namun masih termasuk dalam kategori ringan. Aktivitas yang banyak dilakukan pada kelompok ini adalah bermain ringan di teras rumah seperti main boneka, robot-robotan, mobil-mobilan, dan permainan ringan yang lainnya. Biasanya mereka bermain di rumah teman secara bergantian. Mereka bermain setelah jam pulang sekolah sampai sore sebelum mengaji. Sedangkan pada akhir pekan mereka bermain dari pagi sampai menjelang maghrib dan pulang hanya saat jam makan siang dan mandi saja.

Aktivitas fisik adalah setiap gerakan fisik sebagai hasil dari adanya kontraksi otot skeletal dan diukur sebagai pengeluaran energi. ${ }^{22}$ Jika energi yang berasal dari asupan makan tidak digunakan untuk melakukan aktivitas fisik maka energi akan disimpan di dalam tubuh sebagai jaringan lemak. $^{23}$ Hal ini dapat menyebabkan terjadinya obesitas. ${ }^{22}$ Anak-anak disarankan melakukan aktivitas fisik setidaknya 60 menit setiap hari. ${ }^{21}$ Semakin banyak aktivitas fisik yang dilakukan maka semakin banyak pula energi yang diperlukan. ${ }^{22}$ Namun, kemajuan teknologi yang semakin modern menyebabkan anak cenderung pasif. ${ }^{11}$

Hasil penelitian ini sejalan dengan hasil penelitian di Toronto yang menunjukkan bahwa aktivitas fisik pada anak di daerah urban dan suburban tidak terdapat perbedaan. ${ }^{25}$ Penelitian lain menunjukkan bahwa anak yang tinggal didaerah urban lebih memilih untuk menghabiskan waktu setidaknya dua jam untuk menonton televisi atau video, bermain komputer dan game yang ada di komputer. ${ }^{2,12}$ Hal tersebut menyebabkan anak cenderung pasif dan memiliki gaya hidup santai sehingga aktivitas mereka kurang. ${ }^{11}$ Lembaga kesehatan di Amerika Serikat pada tahun 2011 merekomendasikan pentingnya aktivitas fisik selama satu jam setiap hari. ${ }^{26,27}$ Aktivitas yang dapat dilakukan pada anak dapat berupa kejar - kejaran, lempar bola, bersepeda, berenang, bola kaki, jalan atau lari pagi. ${ }^{28}$

Perbedaan Status Gizi pada Anak Usia Taman Kanak-Kanak di Daerah Urban dan Suburban

Status gizi anak adalah keadaan kesehatan anak yang ditentukan oleh derajat kebutuhan fisik energi dan zat-zat gizi lain yang diperoleh dari pangan dan makanan yang dampak fisiknya diukur secara antropometri. ${ }^{18}$ Pengukuran status gizi pada anak usia 4-5 tahun dalam penelitian ini diukur berdasarkan z-skor menurut IMT/U. Rerata z-skor pada kedua kelompok termasuk dalam kategori normal yaitu 1,07 SD pada kelompok urban dan 0,40 SD pada kelompok suburban. Hasil penelitian menunjukkan terdapat perbedaan status gizi pada anak usia 4-5 tahun di daerah urban dan suburban $(p=0,050)$. Adanya perbedaan antara kedua kelompok dipengaruhi oleh status sosial ekonomi.

Perbedaan wilayah antara kedua kelompok mempengaruhi status sosial ekonomi yang akan berdampak pada ketersediaan pangan. Kelompok urban yang memiliki status sosial ekonomi menengah keatas lebih mudah dalam mengakses dan menyediakan makanan untuk anak mereka. Hal ini dapat mempengaruhi status gizi anak. Sebagian besar anak pada kelompok suburban berasal dari keluarga berstatus ekonomi menengah kebawah. Hal ini berpengaruh terhadap ketersediaan makan yang berdampak pada status gizi anak. Faktor ini yang mempengaruhi adanya perbedaan status gizi pada kedua kelompok tersebut. Penelitian di Pakistan menunjukkan bahwa masyarakat ekonomi menengah kebawah memiliki risiko kekurangan gizi akibat kurangnya asupan. ${ }^{6}$ Penelitian lain menunjukkan bahwa semakin kecil pendapatan keluarga, maka semakin besar persentase anak yang kekurangan gizi. ${ }^{5}$

\section{SIMPULAN}

Tidak terdapat perbedaan asupan energi dan aktivitas fisik antara anak usia 4-5 tahun pada TK di daerah urban dan suburban. Terdapat perbedaan status gizi antara anak usia 4-5 tahun pada TK di daerah urban dan suburban. Rerata status gizi anak pada kelompok urban lebih tinggi dibandingkan dengan rerata status gizi anak pada kelompok suburban. 


\section{SARAN}

Bagi orang tua disarankan untuk memberikan asupan makan yang lebih bervariasi agar anak memiliki pola makan yang seimbang. Asupan makan dan aktivitas anak juga harus seimbang untuk mengontrol berat badan anak agar mencapai status gizi normal.

\section{DAFTAR PUSTAKA}

1. Dep.Kes R.I.Profil Kesehatan Nasional, Jakarta. 2001.

2. Tee ES. Nutrition in Malaysia: where are we heading?. Malaysian Journal of Nutrition 5: 1999.

3. Swinburn BA, Caterson I, Seidell DC, James WPT. Diet, Nutrition and the prevention of excess weight gain and obesity. Publ Health Nutr. 2004; 7 (1A): 123-46.

4. Kementrian Kesehatan. Riset Kesehatan Dasar (Riskesdas). Kemenkes RI; Jakarta. 2010.

5. Lutviana dan Budiono. Prevalensi dan Determinan Kejadian Gizi Kurang pada balita (Studi Kasus pada keluarga Nelayan di Desa Bajomulyo Kecamatan Juwana Kabupaten Pati). Jurnal Kesmas. 2010; vol 5 (2); 165-172.

6. Khan, Khattak and S, Ali. Malnutrition and Associated Risk Factors in Pre-School Children (25 years) in District Swabi (NWFP) - Pakistan. J. med. Sci, 2010; 10 (2); 34-39.

7. Lubis, Ritayani. Hubungan Pola Asuh Ibu dengan Status Gizi Anak Balita di Wilayah Kerja Puskesmas Pantai Cermin Kecamatan Tanjung Pura Kabupaten Langkat (skripsi). Universitas Sumatera Utara; 2008.

8. Sleedens EFC, Kremers SPJ, Vries NKD, Thijs, C. Relationship between parental feeding style and eating behaviours of Dutch children aged 6- 7. 2009; Appetite, 54, 30 - 36 .

9. Horn MG, Galloway AT, Webb RM, Gagnon SG. The role of child temperament in parental child feeding practices and atitudes using a subling design. 2011; Appetite, 57, 510 - 516.

10. Yulia, Cica. Pola Asuh Makan dan Kesehatan Anak Balita pada Keluarga Wanita Pemetik Teh di PTPN VIII Pangalengan (thesis). Bogor : Institut Pertanian Bogor; 2009.

11. Williams, Lipincott and Wilkins. Developmental and behavioural pediatrics, handbook for primary care. Second edition. 2005.

12. Anderson PM, Butcher KF \& Levine PB. Economic perspective on childhood obesity. Economic Perspective, 2003; 3: 30-32.

13. Constantinos A. Loucaides, Sue M. Chedzoy, Neville Bennett. Differences in physical activity levels between urban and rural school children in Cyprus. Health Education Research Vol.19 no.2. 2004.

14. Bintarto R. Pengantar Geografi Kota. Yogyakarta : LIP Spring . 1997.

15. Cynthia AD. Asuhan Gizi, Nutritional Care Process. Yogyakarta : Graha ilmu. 2012.
16. Sjostrom M, Ekelund U, Yngue A. Assessment of Physical Activity. Di dalam : Gibney MJ, Margetts BM, Kearney JM, Arab L, editor. Public Health Nutrition Oxford : Blackwell Publishing. 2008.

17. Kemenkes Indonesia. Kepkemenkes No. 1995/MENKES/SK/XII/2010 tentang Standar Antropometri Penilaian Status Gizi Anak. Kemenkes RI; Jakarta. 2011.

18. Supariasa IDN, Bachyar B, Ibnu F. Penilaian Status Gizi. Jakarta : EGC; 2002.

19. Saelens BE, Seeley RJ, van Schaick K, Donnelly LF, O'Brien KJ. Visceral abdominal fat is correlated with whole-body fat and physical activity among 8y-old children at risk of obesity. Am J Clin Nutr 2007;85:46-53.

20. Snetselaar, L. Nutritional Counseling for Lifestyle Change. New York : CRC Taylor and Fancis Group. 2006.

21. U.S. Department of Health and Human Services. 2008 Physical activity guidelines for Americans. Washington, DC: U.S. Department of Health and Human Services; 2008.

22. WHO, 2010; Physical Activity. In Guide to Community Preventive Services Web site, 2008

23. Aycan, Zehra. Obesity in Childhood : Definition and Epidemiology. J Clin Res Ped Endo 2009;(Suppl 1):44-53

24. Williams, Lipincott and Wilkins. 2005. Developmental and behavioural pediatrics, handbook for primary care. Second edition.

25. Stone MR, Faulkner GE, Mitra R, Buliung R. Physical Activity Patterns of Children in Toronto : the Relative Role of Neighbourhood Type and Socio-economic Status. Can J Public Health. 2012 Jul 23; 103 (9 Suppl 3): eS9-14.

26. Australian Government Department of Health and Ageing. (2004). National children and youth physical activity recommendations.

27. Institute of Medicine (IOM). Early Childhood Obesity Prevention: Policies

28. Kurniasih, Dedeh. Hilmansyah, Hilman. Astuti, Marfuah Panji. Imam, Saeful.Sehat dan Bugar Berkat Gizi Seimbang. 2010. Jakarta : PT.Gramedia 